\title{
A DESCRIPTIVE MODEL OF CHOICE FOR SITING FACILITIES
}

Howard Kunreuther, John Lathrop, and Joanne Linnerooth

International Institute for Applied Systems Analysis, Laxenburg, Austria

\section{RR-82-39}

November 1982

Reprinted from Behavioral Science, volume 27 number 3 (1982)

INTERNATIONAL INSTITUTE FOR APPLIED SYSTEMS ANALYSIS

Laxenburg, Austria 
Research Reports, which record research conducted at IIASA, are independently reviewed before publication. However, the views and opinions they express are not necessarily those of the Institute or the National Member Organizations that support it.

Reprinted from Behavioral Science, 27(3):281-297, by permission of James Grier Miller, M.D., Ph.D., Editor.

Copyright (C) 1982 by the General Systems Science Foundation.

All rights reserved. No part of this publication may be reproduced or transmitted in any form or by any means, electronic or mechanical, including photocopy, recording, or any information storage or retrieval system, without permission in writing from the copyright holder. 


\section{FOREWORD}

The IIASA Risk Group investigates the way in which societies, with their different cultural and institutional styles, make policy decisions on problems involving a risk to the health and safety of the population. An ongoing project* is concerned with the decisions in four countries - the Federal Republic of Germany, the Netherlands, the United Kingdom, and the United States - to site a liquefield energy-gas terminal on the coastline. This technology has a very low probability of an accident involving people living within its vicinity. It therefore presents a special challenge to political decision making with respect to whether the facility should be built and, if so, where it should be located. The decision usually involves many interest groups, each of which is concerned with a number of attributes associated with the final decision, e.g., the provision of energy, the jobs created, and the risks to local residents.

This article develops a descriptive model of siting procedures in the United States (California) that can aid the reader in understanding the complex, interactive process in which the siting decision is made. This work has been expanded to include each of the four countries in a report entitled Risk Analysis and Decision Processes: The Siting of LEG Facilities in Four Countries, which offers a comparative view of how societies cope with low-probability, high-consequence events.

ALEC LEE

Chairman

Management and Technology Area

\footnotetext{
*This project is funded by the Bundesministerium für Forschung und Technologie (BMFT) of the Federal Republic of Germany.
} 


\title{
A DESCRIPTIVE MODEL OF CHOICE FOR SITING FACILITIES
}

\author{
by Howard Kunreuther, John Lathrop, ${ }^{2}$ and Joanne Linnerooth
}

International Institute for Applied Systems Analysis, Laxenburg, Austria

The siting of facilities for large-scale, novel technologies presents a formidable challenge to political risk management. This paper develops a model for describing the decision process for this type of problem at the level of societal systems. It explicitly considers the role of the relevant interested parties, each of whom brings to the siting debate its own set of objectives and attributes. We have labeled the approach a multiattribute multiparty model (MAMP to distinguish it from prescriptive techniques such as multiattribute utility analysis or decision analysis).

The MAMP model is a natural extension of the burgeoning literature on the key role that limited time, attention, and information processing capabilities play in political decision making when there are uncertain outcomes and likely conflicts among interested parties. The model also highlights the importance of decentralized and sequential decision making and indicates the role that formal risk assessments have played at each stage of the process. We illustrate its application in the context of the decision process associated with a proposed liquiefied natural gas terminal in California. The concluding portion of this paper suggests future research needs for improving the credibility of analysis and facilitating collective action with respect to facility siting problems.

\section{INTRODUCTION}

$\mathrm{L}$ ARGE-SCALE, novel technologies such as nuclear power or liquefied natural gas (LNG) promise to yield benefits to society, but only at the cost of potential catastrophic losses. Thus, the siting of the facilities for these technologies presents a formidable challenge to political risk management processes. There are two features of these problems which make them particularly difficult to structure analytically. First, unlike most private market transactions, the selection of a site for these facilities affects many different individuals and groups. People, regardless of personal preference, are exposed to the same risks which may produce conflicting views as to what alternatives are acceptable. Proposed LNG projects are thus examples of public goods. (For a more detailed description of the characteristics of public goods see Stokey \& Zeckhauser, 1978, pp. 305-308.)

${ }^{1}$ This paper is printed with the permission of the International Institute for Applied Systems Analysis, 2361 Laxenburg, Austria. Views or opinions expressed in it do not necessarily reflect those of the National Member Organizations supporting the Institute or of the Institute itself.

The research reported in this paper is supported by the Bundesministerium fuer Forschung and Technologie, F. R. G., contract no. 321/7591/RGB 8001 . While
A second feature of the siting problem is the absence of a data base which provides conclusive statistical evidence on the likely performance of the new technology and the probability distribution associated with potential accidents. Each of the interested parties may, thus, provide different estimates of the chances and consequences of certain events. There are no objective measures to settle these differences.

This paper describes a model of the decision-making process for problems such as the siting of facilities based on new technologies. Different elements of society are affected by these projects and there are limited statistical data bases on the associated risks. The model considers the role of the many interested parties and their specific concerns. It emphasizes the potential for conflict emerging among the interested parties as a result of their differing objectives, mandates, and information sources.

support for this work is gratefully acknowledged, the views expressed are the authors' own and are not necessarily shared by the sponsor. We greatly benefited from earlier discussions with Nino Majone and Chris Mandl, Louis Miller, Michael Stoto, and Detlof von Winterfeldt for their helpful comments on a preliminary draft of this paper.

${ }^{2}$ Dr. Lathrop is now at Woodward-Clyde Consultants, San Francisco. 
We have labeled it a multiattribute multiparty (MAMP) approach to distinguish it from the prescriptive techniques developed in the literature such as multiattribute utility models or decision analysis.

The MAMP model serves two principal purposes. A central focus of a IIASA research project is an analysis of the siting decision concerning liquefied natural gas terminals in four countries (the Federal Republic of Germany, the United Kingdom, the Netherlands, and the United States). A discussion of the factors influencing the siting process in different countries appears in Kunreuther, Linnerooth, and Starnes (in press). The MAMP model has enabled us to standardize our presentation. In a more general sense, it may be a useful tool for undertaking comparative analyses across cultures and across problems.

Secondly, the MAMP model is a natural extension of the burgeoning literature in the social sciences on the key role that limited time, attention, and information processing capabilities play in political decision making where there are uncertain outcomes and likely conflicts among interested parties. It, thus, reflects the importance of understanding decision processes as a first step in trying to improve the way society copes with these types of public goods.

We illustrate the application of MAMP in the context of one of our four case studiesthe siting of an LNG terminal in California. A brief description of the nature of the problem provides a perspective on this case. Liquefied natural gas (LNG) is a potential source of energy which requires a fairly complicated technological process that has the potential, albeit with very low probability, of creating severe losses. For purposes of transporting, natural gas can be converted to liquid form at about 1/600 its gaseous volume. It is shipped in specially constructed tankers and received at a terminal where it undergoes regasification and is then distributed. The entire system (i.e., the liquefaction facility, the LNG tankers, the receiving terminal, and regasification facility) can cost more than $\$ 1$ billion to construct (Office of Technology Assessment, 1977). In 1974, three LNG terminals were proposed for California. After seven years of negotiations, hearings, and studies, on three levels of government, there is still no approved site for any of the proposed terminals in California. (A more detailed discussion of the California siting process appears in Kunreuther \& Lathrop, in press; Lathrop, 1981; Linnerooth, 1980.)

The paper is organized as follows. In section II we briefly specify the conceptual foundations of the MAMP model. Section III provides a more formal structural building on concepts first proposed by Braybrooke (1974). In section IV we show how the decision process for LNG siting in California can be examined through the use of the model. Section V suggests ways that the MAMP model can help to understand better the societal decision-making process. The concluding section suggests future research needs for improving the process.

\section{RELEVANT CONCEPTS}

\section{Bounded rationality}

The theoretical and empirical literature on decision processes in organization theory and political science form the basis for the development of the MAMP model. We review some of the important concepts below. There is a growing recognition in the political science literature that decision makers are limited in their ability and desire to collect information on which to base their actions. They thus attempt to satisfice rather than optimize. One of the earliest descriptions of this bounded rational behavior in the context of societal decision making is by Lindblom (1959) where he contends that the political process is one of incremental muddling rather than comprehensive choice. Instead of examining the full range of alternatives available, government agencies or politicians focus only on a limited set of options. They proceed incrementally by comparing the results of each new policy with old ones, thus drastically simplifying the decision-making process from the one implied by the classical rational model of choice (Braybrooke \& Lindblom, 1963).

Implicit in the concept of incremental decision making is the assumption that individuals and interested parties have a very limited amount of time available to deal with any particular problem. An excellent illustration of this feature of political deci- 
sion making is Wildavsky's (1964) analysis of the Us budgetary process. Due to the complex structure and myriad sets of figures in the budget it is necessary for officials to employ simplified tools in making their choices. One of the principal ways budget officials justify their actions is to use last year's budget as a guide. In fact, Wildavsky points out that:

Budgeting is incremental, not comprehensive... Thus, the men who make the budget are concerned with relatively small increments to an existing base. Their attention is focused on a small number of items over which the budgetary battle is fought. (p. 15)

\section{Multiple parties and multiple issues}

The literature in both organization theory and political science provides an important perspective on the societal decisionmaking process by stressing the role of multiple parties, each of whom have their own goals and objectives. For example, March and Simon (1958) and Cyert and March (1963) view the organization as a coalition of parties, each of which imposes different demands on the system. The goals of the firm arise through a process of bargaining among potential coalition members. In a similar vein, Neustadt (1970), in his later reflections on presidential power, points out that each of the interested parties in the government has its own interests and separate responsibilities. Policy emerges as a result of political bargaining among the actors.

One of the finest studies illustrating the importance of multiple parties in the decision-making process is Allison's (1971) analysis of the Cuban missile crisis. Of the three models he develops to explain the way policy is made, his Government Politics Model (Model III) comes closest to our view of the societal decision-making process. Allison points out that in decision-making situations there are many actors who are in the game as players. Each of them focuses on multiple problems rather than a single issue and have a set of national, organizational, and personal goals. The parties share power and have conflicting preferences. In order to determine how a particular decision emerges, it is necessary to identify the var- ious issues which are deemed important, to indicate what bargains and compromises emerged, and to "convey some feel for the confusion" (p. 146).

\section{Conflicts and agendas}

If there are competing parties in the societal decision-making game, then there are likely to be emerging conflicts. One of the important questions which has been studied in recent years is how these potential conflicts are handled. Cyert and March (1963) hypothesize that conflict is rarely resolved in an organization, but that sequential and decentralized decision making enable actions to be taken in many situations even if there are inconsistent goals between the parties. The importance of these features of the organizational decision-making process in the context of political decision making is highlighted by the following quote from Simon (1967):

Influence over the direction of attention of the political organs is a principal means for affecting action. The notion of power as a tug-of-war between alternatives yields to a notion of power as influence on a sequential process in which actions must be generated as well as chosen and in which attention is a scarce resource (p. 108).

This characterization of the decision process is similar to the one formulated by Allison, who suggests that each one of the parties in the game faces an agenda with hundreds of deadlines, not all of which are being met. There is, thus, a need for some type of prioritization among items. In other words one needs to consider the nature of the agenda-setting process. As one would expect, these items which are placed on the legislative agenda become an important determinant of the final decisions which will be taken by society.

Cobb and Elder (1972) indicate that an important way that an issue gets placed on the agenda is through some type of exogenous event which creates conflict. They illustrate this phenomenon using the example of the passage of the Federal Coal Mine and Safety Act of 1969, designed to reduce deaths from mine accidents and protect miners from black lung disease. The legislation was triggered initially by a cave- 
in of a West Virginia coal mine which trapped and eventually killed 78 miners. This disaster caused the miners to strike, which brought pressure on the state and federal government to react to the miners' concerns.

In another context, Holling (1981) has pointed out how specific crises in the shortrun can lead to changes in policies with respect to environmental and ecological problems (e.g., the suppression of the spruce budworm after it had destroyed forests in Canada). Kunreuther and Lathrop (in press) describe with specific examples how exogenous events triggered new coalitions and new legislation regarding LNG siting decision in the United States.

One reason for the importance of exogenous events, such as crises and disasters, in triggering societal interest in a specific problem is that it is easily understood evidence of trouble. Walker (1977) stresses the importance of this factor in setting the discretionary agenda of the Us Congress or a government agency. To support this point, Walker presents empirical evidence on the passage of safety legislation in the United States.

\section{Sequential processing of issues}

Braybrooke $(1974,1978)$ has developed an interesting concept of the political system which he views "as a machine or collection of machines for processing issues." In contrast to the static theory of collective choice based on the pioneering work of Arrow (1963), Braybrooke views the decision-making process as sequential and constantly changing. At any point in time there is an issue or set of issues which involve a set of interested parties. Over time particular issues may be resolved, disappear, or be transformed as new information or new alternatives emerge. In particular, new proposals may be constructed to reflect either the changes in preferences of the interested parties and/or a revised set of societal values.

The importance of Braybrooke's work is that it enables one to decompose a problem into smaller subproblems by focusing on relevant issues. It, thus, captures the sequential decision-making process which characterizes individual and organizational problem solving (March, 1978) as well as the public policy-making process (Gershuny, 1981).

The setting of an agenda is likely to play a role in determining the final outcome emerging from this sequential decision process. Empirical evidence from the field as well as from laboratory experiments (Levine \& Plott, 1977) indicates that the order in which specific subproblems are considered frequently leads to different outcomes for the same broader question.

We expect the same order effect for societal decision-making problems for two principal reasons. Once a particular decision has been made on a particular issue, this serves as a constraint for the next set of issues. If the order of the issues is reversed, then there is likely to be a different set of choices to consider. Second, each issue involves a different set of interested parties who bring with them their own set of data to bolster their cause. The timing of the release of this information may have an effect on later actions. For example, citizen groups normally enter the scene with respect to siting problems only when their own community is being considered as a possible candidate. The order in which different locations are considered is, thus, likely to influence the final outcome of the siting debate.

\section{Summary}

In summary there is a large body of literature which has emerged in recent years suggesting that the societal decision-making process is one where there are a number of interested parties who have their own goals and objectives. Each actor has his own set of information which he uses to defend specific recommendations. As a way of reducing potential conflicts, the decisionmaking process is frequently sequential and decentralized, since many items are competing for limited time and attention. The process of agenda building is an important element in understanding why certain problems are considered important and others are ignored. Recent empirical studies have stressed the importance of exogenous events as an important variable in explaining this process. Political decision making 
is likely to follow a sequential process whereby new issues emerge through the resolution of previous issues, changes in party preferences, and/or social norms.

\section{STRUCTURE OF THE MAMP MODEL}

The above concepts are now incorporated into a model of a sequential decision process which involves different interested parties at each stage. The model views political decision making in terms of the concepts discussed in the previous section. It should be viewed as a first step in characterizing societal decision making with limited information.

Rounds. The decision process can be separated into different rounds which label by capital letters $A, B, \ldots$ A round is simply a convenient device to illustrate a change in the focus of discussions. This new focus or direction can be triggered by (1) a key decision taken (or a stalemate reached due to conflicts among parties), or (2) a change in the context of the discussions due to an unanticipated event, the entrance of a new party or new evidence brought to the debate. Although we will treat rounds as sequential in our illustrative case study, they may also be overlapping.

Problem formulation. The decision process in each round is characterized by a unique problem formulation phase. The alternatives for discussion are bounded by specific constraints. These include legislative and legal mandates requiring specific parties to be part of the debate, resource constraints which have the effect of limiting certain parties from exerting an influence because they do not have adequate funds and means, and prespecified voting procedures indicating what parties have the power to influence the outcome of specific decisions and in what ways. The previous decisions already taken will also influence the way the problem is formulated. In this sense the agenda-setting process will have an impact on final outcomes.

A round of discussions is initiated by a formal or informal request. Informal discussions may be initiated simply by such actions as a request for information on the part of one of the parties or a request for preliminary discussions. Because the par- ticular form of these initiating requests may further define or limit the bounds of the discussion, the careful scrutiny of their wording is important. For example, it may make a difference in the decision process if the question is framed as "which site, if any, is appropriate?", or "whether one of the proposed sites $x, y$, and $z$ is appropriate?" Belnap and Steel (1976) refer to the first question as a "which question" and the second as a "whether" question. Whether questions demand more complicated considerations and detailed thinking while which questions can be approached with simpler rules of thumb and heuristics.

Alternatives, attributes, and decisions. No matter how a round is initiated it is characterized by a unique problem formulation which is presented in the form of a limited set of alternatives due to information processes, limitations, and the constraints affecting the interested parties.

We define the alternatives for round $A$ to be $A^{1}, A^{2}, A^{3}, \ldots$; round $B$ has alternatives $B^{1}, B^{2}, B^{3} \ldots$ There can be several decisions made in any round, but by definition they are based on the same set of alternatives. In other words, if the set of alternatives change, we will treat this as a new round. (Two rounds, however, can utilize the same alternatives. The difference between the rounds may be due to a revised problem formulation, e.g., new legislation or constraints.) Each alternative is characterized by a set of attributes $X_{1} \ldots Y_{1_{n}}$. The value of any attribute can change from round to round on the basis of new information or perceptual changes. For certain attributes any party involved may have target or aspiration levels which determine whether he considers a particular alternative in round $A$ to be acceptable with respect to attribute $X_{i}$.

Another important feature of the decision process is that the value of an attribute to the same interested party can change over time because of new information. For example, if a report provides new insight into the seismic risk associated with a particular site, this may cause a change in the perception of this attribute by one or more of the parties involved. That change may take the form of a different estimate of the 
level of the attribute for that site, or perhaps a different weight given to the relative importance for the attribute.

Interaction phase. To understand a particular pattern of institutional choice it is necessary to analyze a set of policy actors $\{P\}$, their respective power positions, their interactions with one another at different stages of the process, and the information available to them. We define $P_{k}$ to be the $k$ th interested party in the debate. Its evaluation of alternative $A^{1}$ is based on its estimation of the levels and values of each attribute resulting from that option, and the relative importance given to each attribute. Another party might have different estimates of the effects of an option, different costs and benefits resulting from those effects, or assign different relative importance to each of the attributes. Because of any of these differences one party may rank alternatives differently than another. As we shall see in our analysis of the California case this happened frequently. Thus, in the case of two interested parties and two alternatives it is possible that party 1 prefers $A^{1}$ to $A^{2}$, while party 2 has the reverse reaction.

The interaction among the parties is represented by the main arguments each brings to the debate in support of or in rejection of each of the alternatives at hand. Those arguments may relate to only one or two attributes. It is not suggested here that the arguments presented for or against a particular proposal necessarily reflect a concern of the party making the argument. For example, a party opposed to a site because of its concern for environmental quality may present an argument using seismic risk as the main reason to reject the site. The argument attribute may be selected to maximize the effectiveness of the argument, not to reflect the actual concern of the party. The argument reflects a strategy on the part of the actor in support of or opposition to the proposal. The strategy of the actors can reveal a number of underlying motives and desires of those concerned and may be essential in understanding the interpretation and use of scientific evidence, including risk analyses.

The interaction phase provides useful in- sights into the process. Parties often come into the debate with firm preferences. The interaction phase brings out their arguments, i.e., attributes and perceptions, and may change their positions on an issue. The stability of the system can, at least partially, be judged by the degree to which the actors-people holding certain recognized positions (i.e., officials, experts, group leaders) or collections of these people, whether formally organized institutions or loosely working alliances-remain the same after each successive round.

The outcome of the political debate results, to a large extent, from some combination of the political power on the part of the parties involved, the attention they give to the issues in light of their limited resources and time, the way in which the problems on the political agenda are framed, and the exogenous events that may change the problem and/or the parties. The interaction phase can be thought of as the formal and informal communication among the parties influencing the decision outcome. Wynne (1981) has shown the futility of assuming that parties interact as "rational" actors in the sense of actively and openly pursuing clearly defined objectives, but that defensive behavior, that is, the avoidance of problems and dangers, may be no less rational than goal-directed behavior.

In addition, Majone (1979) points out that organizational behavior is usually not directed at problem solving in any rational sense, but rather at serving the longer-run interests of the organization or institution. In the public domain, as opposed to the market, decisions must be justified with seemingly objective arguments, and a consensus within and/or beyond an organization can only be reached with convincing and institutionally appropriate arguments. Therefore, the arguments made by the parties, though they cannot be interpreted as representing clearly defined goals, are important insofar as they reveal the complex strategies and counter strategies of those in the policy game.

Concluding a round. The round is concluded by a decision, a stalemate, a change in information (changing the focus of the 


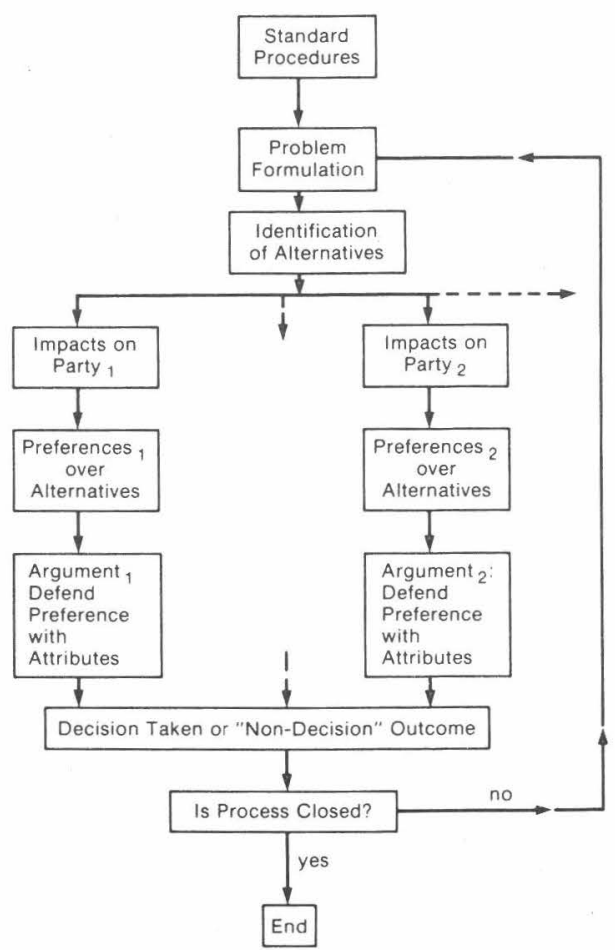

FIG. 1. Multiattribute multiparty (MAMP) model of choice.

debate and, hence, initiating a new round), or an exogenous event (e.g., a disaster) aborting the discussions and requiring a new round of inquiry. Each decision can, in turn, be described by the tradeoffs implicit in the choice made. These tradeoffs may not be explicitly recognized by the decision maker, or not explicitly analyzed in the process of making the decision.

Fig. 1 provides a schematic diagram of the MAMP model. In the problem formulation phase of each round certain constraints circumscribe the issues. An initiating event determines the limited set of alternatives $\left\{J^{1}, J^{2} \ldots\right\}$ which, in turn, induce a set of interested parties $\left\{\boldsymbol{P}_{k}\right\}$ to enter the scene. Each of these parties has its own preferences for a given set of alternatives; these preferences are defended by a set of attributes. The interaction process results either in a clear decision or an outcome that does not have the appearance of a decision but that does conclude the round.
The conclusion of round $J$ can take one of two forms. If there is a feasible and agreed-upon solution or if no solution is possible, the process ends. However, if one or more parties is unsatisfied with the situation at the end of the round, and has recourse to other channels, or if the round ends in a request for further action, a new problem is formulated for round $J+1$ and the above sequence is repeated for another set of alternatives, interested parties (some or all may be the same as in $J$ ), etc.

\section{APPLYING MAMP: THE SITING OF THE CALIFORNIA LNG TERMINAL}

In this section we will apply the MAMP framework to the question of whether California should have an LNG terminal. We will first specify the relevant interested parties, and then focus on the actual decision process.

\section{Interested parties and relevant attributes}

To structure the siting process we need to have a good understanding of the different concerns of the interested parties. For the LNG problem there are three categories of concern which are relevant: risk aspects, economic aspects, and environmental aspects. Each of these concerns can be described by a set of attributes. Table 1 depicts an interested party/attribute matrix showing the main concerns of each of the relevant groups over this seven-year period.

The attributes listed have been selected to reflect the nature of debates in the process, that is, to reflect the attributes as perceived by the parties in the debate, rather than to characterize in some logical analytical manner the alternatives. For example, population risk $\left(X_{2}\right)$ involves the risk to life and limb to neighbors of the LNG terminal due to accidents, including those induced by earthquakes. Earthquake risk $\left(X_{3}\right)$, which involves both population risk and supply interruption risk due to earthquakes, is included as a separate attribute since it was handled as such in the process.

The filled cells in Table 1 indicate which parties pay particular attention to which attributes. Naturally, many of the parties care about all the attributes listed. However, either because of the incentives di- 
TABLE 1

Principal Party-by-Attribute Matrix for lng Siting in California.

\begin{tabular}{|c|c|c|c|c|c|c|c|c|c|}
\hline \multirow{4}{*}{ Attributes } & & \multicolumn{8}{|c|}{ Principal Parties* } \\
\hline & & \multirow{3}{*}{$\begin{array}{c}\text { Applicant } \\
\begin{array}{c}\text { Utilities } \\
P_{1}\end{array}\end{array}$} & \multicolumn{5}{|c|}{ Government } & \multirow{2}{*}{\multicolumn{2}{|c|}{ Interest Groups }} \\
\hline & & & \multirow{2}{*}{$\begin{array}{c}\text { Federal } \\
\\
\text { FERC } \\
P_{2}\end{array}$} & \multicolumn{3}{|c|}{ State } & \multirow{2}{*}{$\begin{array}{c}\text { Local } \\
\text { Municipal } \\
\text { Govern- } \\
\text { ment } \\
P_{b}\end{array}$} & & \\
\hline & & & & $\begin{array}{c}\mathrm{CCC} \\
P_{3}\end{array}$ & $\begin{array}{c}\mathrm{CPUC} \\
P_{4}\end{array}$ & $\underset{P}{\text { Legislature }}$ & & $\begin{array}{c}\text { Sierra } \\
\text { Club } \\
P_{i}\end{array}$ & $\begin{array}{c}\text { Local } \\
\text { Citizens } \\
P_{8}\end{array}$ \\
\hline \multicolumn{10}{|l|}{ Risk } \\
\hline supply interruption & $X_{1}$ & - & - & & 0 & • & & & \\
\hline population & $X_{2}$ & & 0 & - & 0 & 0 & - & - & - \\
\hline earthquake & $X_{3}$ & & - & - & 0 & - & & & \\
\hline \multicolumn{10}{|l|}{ Environmental } \\
\hline air quality & $X_{4}$ & & - & & - & - & & 0 & \\
\hline land use & $X_{5}$ & & 0 & - & - & - & - & 0 & 0 \\
\hline \multicolumn{10}{|l|}{ Economic } \\
\hline profit considerations & $X_{6}$ & - & & & & & & & \\
\hline price of gas & $X_{-}$ & & - & & 0 & - & & & \\
\hline local economic benefits & $X_{\star}$ & & & & & & - & & \\
\hline
\end{tabular}

* Key to party acronyms and abbreviations: FERc: Federal Energy Regulatory Commission, or, in the furst two rounds of the process, its preceding agency, the Federal Power Commission; ccc: California Coastal Commission; cpuc: California Public Utilities Commission; Legislature: California State Legislature.

rectly felt by the party or because of the role the party plays in society, each party makes its decisions as a function primarily of a particular subset of the attributes.

The applicant, Western LNG Terminal Associates, was a special company set up to represent the LNG-siting interests of three gas distribution utilities: Southern California Gas Company, Pacific Gas and Electric, and El Paso Natural Gas Company. As domestic gas supplies seemed to be diminishing in the late $1960 \mathrm{~s}$, the gas utilities perceived an increased risk of supply interruption, which could be mitigated by additional supplies such as LNG. Quite naturally, the applicant was primarily concerned with profitability $\left(X_{6}\right)$ and secure supplies of gas $\left(X_{1}\right)$.

At the various government levels there are five principal parties. The Federal Energy Regulatory Commission (FERC) in the Department of Energy is the principal body at the federal level which determines whether a proposed LNG project is in the public interest and should be allowed. In making its judgment it considers primarily the following attributes: risk factors $\left(X_{1}, X_{2}\right.$, and $X_{3}$ ), environmental guidelines as reflected in air quality $\left(X_{4}\right)$ and use of land $\left(X_{5}\right)$ and the expected LNG price $\left(X_{7}\right)$.

Let us turn now to state agencies which play a role. The California Coastal Commission (CCC) was created in 1976, and has the responsibility for the protection of the
California coastline. Its primary concerns with respect to LNG are with the use of land $\left(X_{5}\right)$ and the associated risks $\left(X_{2}\right.$ and $\left.X_{3}\right)$ from building a terminal at a specific site. The California Public Utilities Commission (CPUC) is the principal state body involved in power plant issues and is primarily concerned with the rate-setting process. Hence, the CPUC focused on the provision of energy to California residents and need for gas $\left(X_{1}\right)$ and the proposed price of the product $\left(X_{7}\right)$. In addition, it has responsibility for evaluating the impact that a proposed facility would have on the environment and safety. The California State Legislature is ultimately responsible for the outcome of any siting process. It determines which state and local agencies have final authority to rule on the feasibility of a proposed site. In addition, it can set standards to constrain any siting process. Hence, the concerns of the legislators range over economic, environmental, and safety attributes as shown in Table 1.

At the local level, the city councils evaluate the benefits of a proposed terminal in their jurisdiction in terms of the tax, business revenues, and jobs $\left(X_{8}\right)$ it promises to provide. The councils try to balance this positive feature with the impact that the facility would have on land use $\left(X_{5}\right)$ and risk to the population $\left(X_{2}\right)$. Finally, the public interest groups, represented by the Sierra Club and local citizens groups, are 
primarily concerned with environmental and safety issues. The important message of Table 1 does not lie in the details of exactly which cells are filled, but lies in the generally great differences between columns of the table. That is, the different parties in the process care about very different subsets of the attributes.

\section{The decision process}

The siting process in California (which is not yet terminated) can be characterized by four rounds of discussions as shown in Table 2, which provides a summary of the entire process. Each round, in turn, contains a summary of how the problem was defined, the initiating event, and how the discussions were concluded. The remainder of this subsection discusses in more detail the decision process within each of the rounds. The main elements of rounds $A, B$, $C$, and $D$ are described in Tables $3,4,5$, and 6 , respectively.

Round $A$ began in September 1974, when the applicant filed for approval of three sites on the California Coast-Point Conception, Oxnard,.. and Los Angeles-to receive gas from Indonesia. The application raised two central questions which defined the problem addressed in round $A$ : Does
California need LNG, and if so, which, if any, of the proposed sites is appropriate?

The agenda for discussion was more narrowly defined at this stage. The wheels of the process were set into motion, not by a broadbased energy-policy question initiated in Washington, but by a proposal from industry for three preselected sites. The importance of this process-where the initiative is taken first by industry-in preselecting the agenda for debate cannot be overemphasized. The initiating proposal framed the problem as "Should the proposed LNG sites be approved?, and not "Should California have an LNG terminal in view of the alternatives, costs, risks, etc.?" Setting the agenda in this manner did not preclude the "need" question from entering the debate, but it did ensure that the question was only considered in the context of a siting application.

Table 3 also specifies the relevant interested parties who were involved in the interaction phase of round $A$. Those parties which had formal decision power are marked with an asterisk. There were four primary attributes which were utilized in the ensuing debate among the parties. The need for LNG or the risk of an interruption in the supply of natural gas $\left(X_{1}\right)$ supported

TABLE 2

Summary of Rounds in California lng Siting Case.

\begin{tabular}{|c|c|c|}
\hline Round A & & Date \\
\hline Problem Formulation: & $\begin{array}{l}\text { Should the proposed sites be approved? That is: Does California need LNG, and if so, which, if any, } \\
\text { of the proposed sites is appropriate? }\end{array}$ & \\
\hline Initiating Event: & Applicant files for approval of three sites. & $\begin{array}{l}\text { September } 1974 \\
\text { ( } 34 \text { months) }\end{array}$ \\
\hline Conclusion: & Applicant perceives that no site is approvable without long delay. & July 1977 \\
\hline \multicolumn{3}{|l|}{ Round B } \\
\hline Problem Formulation: & How should need for LNG be determined? If need is established, how should an LNG facility be sited? & \\
\hline Initiating Event: & Applicant and others put pressure on State Legislature to facilitate LNG siting. & $\begin{array}{l}\text { July } 1977 \\
\text { (2 months) }\end{array}$ \\
\hline Conclusion: & $\begin{array}{l}\text { A new siting process is set up that essentially assumes a need for LNG, and is designed to accelerate } \\
\text { LNG terminal siting. }\end{array}$ & September 1977 \\
\hline \multicolumn{3}{|l|}{ Round C } \\
\hline Problem Formulation: & Which site should be approved? & \\
\hline Initiating Event: & Applicant files for approval of Point Conception site. & $\begin{array}{l}\text { October } 1977 \\
\text { (10 months) }\end{array}$ \\
\hline Conclusion: & Site is approved conditional on consideration of additional seismic risk data. & July 1978 \\
\hline \multicolumn{3}{|l|}{ Round D) } \\
\hline Problem Formulation: & Is Point Conception seismically safe? & \\
\hline Initiating Event: & Regulatory agencies set up procedures to consider additional seismic risk data. & \\
\hline Conclusion: & (Round is still in progress.) & \\
\hline
\end{tabular}


TABLE 3

FLEMENTS OF ROUND A.

\begin{tabular}{ll}
\hline Problem Formulation: & $\begin{array}{l}\text { Should the proposed sites be approved? } \\
\text { That is: Does California need } \mathrm{LNG} \text {, and if so, } \\
\text { which, if any, of the proposed sites is appro- } \\
\text { priate? }\end{array}$ \\
Initiating Event: & Applicant files for approval of three sites. \\
Alternatives: & $\begin{array}{l}\text { Site at Point Conception: } \\
\text { Site at Oxnard: }\end{array}$ \\
& $\begin{array}{l}\text { Site at Los Angeles: } \\
\text { Site at any combination of: } A^{3}\end{array}$ \\
&
\end{tabular}

Interaction:

\begin{tabular}{|c|c|c|c|c|c|}
\hline \multicolumn{2}{|c|}{ Involved Parties } & \multicolumn{4}{|c|}{ Attributes Used as Arguments } \\
\hline Applicant & $P_{1}$ & $X_{1}$ & & & \\
\hline${ }^{*}$ FERC & $P_{2}$ & $X_{1}$ & & $X_{3}$ & \\
\hline "ccc & $P_{3}$ & & $X_{2}$ & & \\
\hline *City Councils & $P_{6}$ & & $X_{2}$ & & $X_{5}$ \\
\hline Sierra Club & $P_{7}$ & & $X_{2}$ & & $X_{5}$ \\
\hline Local Citizens & $P_{8}$ & & $X_{2}$ & & $X_{5}$ \\
\hline
\end{tabular}

Key Decisions:

1. ccc concerns over population risk implies that $A^{\prime}$ is preferred over the other two sites.

2. FERC would not approve $A^{2}$ because the seismic risk is greater than a prescribed acceptable level.

Conclusion:

Applicant perceives a stalemate, i.e., that no site is approvable without long delay.

- Interested party with responsibility for decision(s).

the locating of a terminal in at least one of the three proposed sites. While environmental, land-use considerations $\left(X_{5}\right)$ suggested a nonremote site (Los Angeles and Oxnard), the risks to the population $\left(X_{2}\right)$ argued for siting the terminal in a remote area (Point Conception). Finally, concerns about earthquake risk brought about opposition to the Los Angeles site, which was found to be crossed by a significant fault.

The interaction phase of round $A$ (see Table 3) indicates the attributes used as arguments by each of the major involved parties. It is important to distinguish the listing of attributes from that in Table 1. While Table 1 specifies which attributes are of primary concern to each party, Table 3 specifies which attributes were used as arguments by each party. Thus, while the applicant is concerned with both profit considerations and supply interruption risk, its arguments in support of each site stressed supply interruption risk.

Two key decisions were made during round $A$. First, the CCC, concerned about the catastrophic potential of LNG, implied that they were likely to favor Point Con- ception over the nonremote sites due to concerns over population risk. Specifically, the CCC advised Western to pursue at least one site in a remote area since they would deny approval to any nonremote site which was not considered safe. Second, the FERC indicated disapproval of the Port of Los Angeles as an acceptable site because a recently discovered earthquake fault increased the seismic risk above a prescribed acceptable level.

The round was concluded with a possible stalemate, at least as perceived by industry (Ahern, 1980). Los Angles would not receive federal (FERC) approval, Oxnard might not receive state ( $\mathrm{CCC}$ ) approval, and Point Conception would face difficult approval challenges at the county and state (CCC) levels because of its adverse land-use impacts.

The stalemates of round $A$ formulated the problem for round $B$. It was clear to all the parties involved that it was difficult, if not impossible, for the applicant to gain approval for a site under the existing siting procedure in California. In particular, there were possibilities of vetoing proposals at either the federal, state, or local levels as evidenced by the respective reactions to the three proposed sites. Rather than trying to operate within the existing constraints of the process, the interested parties in the process frequently try to change the rules of the game (Majone, 1979).

This behavior relates to the process described by Braybrooke (1978), where he points out that issues are frequently transformed over time. Round $B$ is a good illustration of this process. The problem was redefined into two new questions: How should need for LNG be determined? If need is established, how should an LNG facility be sited? The round was thus initiated when pressure to change the siting procedure was brought to the State Legislature by the utility companies, the business community, and the labor unions in California. Table 4 depicts the relevant alternatives which formed the basis for the debate on the elements of proposed legislation.

The industry and business interests saw the inevitable problem of obtaining local approval for a project in the national interest, but with costs to the local community. 
TABLE 4

Elements of Round B.

\begin{tabular}{ll}
\hline \hline Problem Formulation: & $\begin{array}{l}\text { How should need for LNG be determined? If } \\
\text { need is established, how should an LNG facil- } \\
\text { ity be sited? }\end{array}$ \\
Initiating Event: & $\begin{array}{l}\text { Applicant and others put pressure on state } \\
\text { legislature to facilitate LNG siting. }\end{array}$ \\
Alternatives: & Consider offshore sites: \\
& Consider remote onshore sites: $\quad B^{1}$ \\
& Consider nonremote onshore sites: $B^{2}$ \\
& One-stop licensing: \\
& Licensing Agency: cPuc $=B^{5}$, cCC $=B^{6}$, cEC \\
& $=B^{7 *}$ \\
& Any consistent combination of $\mathrm{B}^{1}$ through \\
& $\mathrm{B}^{7}$.
\end{tabular}

Interaction:

\begin{tabular}{|c|c|c|c|}
\hline Involved Parties & & \multicolumn{2}{|c|}{ Attributes Used for Arguments } \\
\hline Applicant & $P_{1}$ & $\mathrm{x}_{1}$ & \\
\hline $\begin{array}{l}\mathrm{ccc} \\
\text { cPuc }\end{array}$ & $\begin{array}{l}P_{3} \\
P_{4}\end{array}$ & $\mathrm{X}_{2}$ & $\mathrm{X}_{3}$ \\
\hline * State Legislature & $P_{5}$ & $\hat{X}_{1}$ & \\
\hline
\end{tabular}

Key Decisions:

3. Initial legislation introduced which included $B^{1}, B^{2}$, and $B^{5}$.

4. Final legislation passed which incorporated $B^{2}, B^{4}$, and $B^{5}$.

Conclusion:

Passage of LNG Siting Act of 1977 (S.B. 1081) which defines a customtailored siting procedure for LNG. Some features:

- ccc nominates and ranks sites in addition to the one applied for - CPUC selects a site from the CcC-ranked set, not necessarily the top-ranked site.

- $\mathrm{CEC}=$ California Energy Comission

* Interested party with responsibility for decision(s).

So the utility companies battled for a bill (S.B.1081) which would vest the CPUC with one-stop licensing authority, precluding any interference from local communities. The environmental and local interests, on the other hand, objected to a one-stop licensing process and favored a bill which required remote siting.

The resulting legislation was a compromise between the environmentalists, who supported consideration of off-shore sites, and those who saw an urgent need for an LNG facility to assure energy and jobs. The CPUC was chosen over the more conservation-minded $\operatorname{ccc}$ or the California Energy Commission as the agency with state permit authority, preempting local governments. As a bow to the conservationists, the $\mathrm{CCC}$ was given the mandate to choose and to rank possible sites, and to pass these ranking on to the CPUC. It was agreed that the site would not be offshore, as some environmentalists wished, nor could it be in a populated area, as the gas utilities wished.
Indeed, a nonpopulated area was strictly defined. There could be no more than an average of 10 people per square mile within one mile of the terminal, and no more than 60 people per square mile within four miles of the terminal.

The passage of the Siting Act of 1977 (S.B.1081) opened up a new procedure for finding an acceptable site and led to round $C$ with the following problem formulation. Which site should be approved? The round was initiated by the CCC which, after considering 82 sites meeting the remote-siting constraint, ranked the top four sites, Camp Pendleton, Rattlesnake Canyon, Point Conception, and Deer Canyon, in that order, on the basis of seismic, soil, wind and wave conditions, rough cost, and coastal resource considerations. (Point Conception was included in the candidate set because S. 1081 required that the applied-for site be included.)

These four alternatives form the background for the interaction among the interested parties in round $\mathrm{C}$ as shown in Table 5 . The ccc passed these rankings on to the

TABLE 5

Elements of Round C.

\begin{tabular}{ll}
\hline \hline Problem Formulation: & Which site should be approved? \\
Initiating Event: & Applicant files for approval of Point Concep- \\
& tion site. (The only site of the original three \\
& meeting the remote siting constraint of S.B. \\
& 1081)$. \\
Alternatives: & (Sites nominated by ccc plus applied-for \\
& site.) \\
& Site at Camp Pendleton: $C^{1}$ \\
& Site at Rattlesnake Canyon $C^{2}$ \\
& Site at Point Conception: $C^{3}$ \\
& Site at Deer Canyon: \\
\end{tabular}

Interaction:

\begin{tabular}{|c|c|c|c|c|c|}
\hline \multicolumn{2}{|l|}{ Involved Parties } & \multicolumn{4}{|c|}{ Attributes Used for Arguments } \\
\hline Applicant & $P_{1}$ & $x_{1}$ & & & \\
\hline FERC & $P_{2}$ & $\mathrm{X}_{1}$ & & & $\mathrm{X}_{\text {; }}$ \\
\hline $\operatorname{ccc}$ & $P_{i}$ & & & $\mathrm{X}_{3}$ & \\
\hline CPUC & $P_{4}$ & $\mathrm{X}_{1}$ & $\mathrm{X}_{2}$ & & \\
\hline Sierra Club & $P_{7}$ & & & $\mathrm{X}_{3}$ & $\mathrm{X}$ \\
\hline Local Citizens & $P_{\mathrm{s}}$ & & & & $\mathrm{X}_{\mathrm{f}}$ \\
\hline
\end{tabular}

Key Decisions:

5. The ccc has the following preference: $C^{1}>C^{2}>C^{3}>C^{4}$

6. The cPuc approved conditional on whether or not the seismic risk is acceptable.

7. The FFrC consider $C^{1}$ acceptable.

8. Court requires FERC to consider additional data to determine whether or not seismic risk at $C^{z}$ is acceptable.

Conclusion:

FERC and CPUC to consider additional seismic data.

- Interested party with responsibility for decision(s) 
CPUC which chose, by process of elimination, Point Conception, on the grounds that the two higher-ranked sites would involve unacceptable delay and would cause unacceptable risk to transients (i.e., campers, swimmers, etc.) at the nearby beaches and public parks. The CPUC, however, could only conditionally approve Point Conception subject to the utility company's ability to show that earthquake faults discovered in the area presented an acceptable risk to the terminal.

At the federal level, the FERC staff determined that the risks of both Oxnard and Point Conception were acceptably low, so that Oxnard should be preferred on landuse grounds; however, the FERC, choosing to avoid a federal-state confrontation, ruled in favor of Point Conception. After an appeal by the environmental and local interests, the Washington, D.C., Court of Appeals remanded the case back to the FERC on the grounds that not all available seismic risk data were considered by the FERC in its ruling. This decision concluded round $C$.

Round $D$ is still in progress at this time. As shown in Table 6 the initiating proposal is determined by the activities in round $C$ which frame the alternatives as simply whether or not to declare the Point Conception site seismically safe. Only two parties, the FERC and the CPUC are currently active in the process, and they are considering only one attribute-the seismic risk at Point Conception. A final decision will depend upon whether the new studies show

TABLE 6

Elements of Round D.

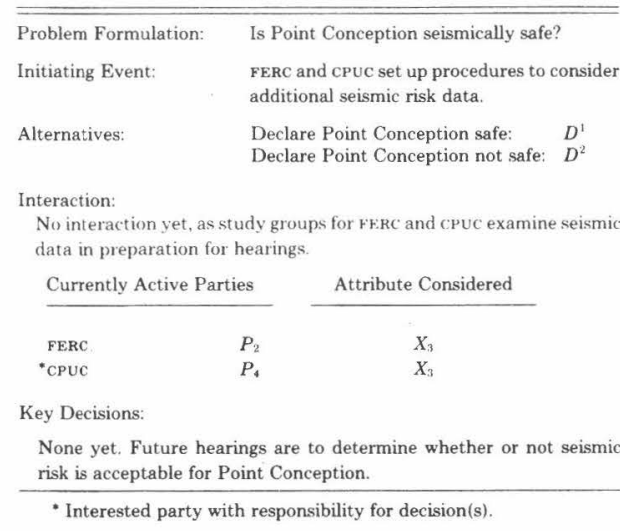

this risk to be above or below some acceptable level.

\section{INTERPRETATION OF THE MAMP MODEL}

The MAMP representation is designed to both describe a political decision process, and to bring structure to that description that might suggest institutional reforms. The California decision process illustrated in this paper can be interpreted from many varied perspectives. It is a good example of conflicting national and local interests; it is a study of the workings of the adversarial nature of U.S. regulatory proceedings; it is a precedent-setting report of procedural practice for setting energy policy; as well as an account of introducing a controversial large-scale technology with a small probability of a catastrophic accident. Clearly, a full exposition of these interpretations would go beyond the scope of this paper. In this spirit we will briefly present two insights from this approach which are of particular interest to the IIASA Risk Group: the importance of sequential decision making and the role that risk analysis has played in the siting process.

\section{The importance of sequential decision making}

The sequential aspect of the LNG siting process in California is crucial for understanding the current situation. During the seven-year course of the process, the need for imported natural gas in California diminished greatly. Instead of examining this need, the interested parties, "locked in" by previous decisions, are now examining the seismic data at a rather slow pace. This is an example of a process of nondecision making where the interested parties are using existing political institutions and procedures to limit the scope of actions. There may be no incentive for anyone to rule on the seismicity of Point Conception if there is now little interest in siting on LNG terminal. (For a more detailed discussion of the role of nondecision making in the political process, see Bachrach and Baratz, 1970.)

A second example of undesirable effects from sequential constraints concerns the risk of an interruption in the supply of natural gas. Initially, the applicant stressed 
supply interruption risk due to shortage of natural gas as a major reason for importing LNG to three separate sites. During the course of the decision process, for reasons beyond the control of the applicant, the three sites were reduced to one site, and the number of storage tanks at that site were reduced from four to two. The planned Point Conception throughput of $58,000 \mathrm{~m}^{3}$ LNG/day, (equivalent in energy flow to roughly 15 modern nuclear reactor units), is large for one geographical location (Mandl \& Lathrop, 1981). Because of this concentration in one small area, and the possibility of routine closures or nondelivery resulting from bad weather, etc., the net result of the sequential decision process is that a project originally meant to decrease supply interruption risk has been shaped over time into a project that may increase supply interruption risk.

The sequential nature of the decision procedures, as clearly demonstrated by the increasing concreteness of the problem formulations through the four rounds of discussions in California, limits the possibilities for comprehensive analyses. The risk studies were carried out, not as an input to a broad energy siting analysis in California, but to support a more narrowly defined problem (Should site $x$ or site $y$ be approved?). Since round $A$ in California was not defined in these narrow terms (the question of whether the terminal was needed was yet to be resolved), the analyses were ill suited to address fully the issues on the table. In some sense, then, analyses designed to address the question of safety were prematurely introduced into a process that had not resolved higher-order questions of energy policy. Though they served to focus the debate on the safety question, they could not offer (nor were they intended to offer) a panacea for the resolution of the siting question. (It is not surprising, then, that round $A$ ended in a stalemate. The second round, where the State Legislature took center stage, narrowed the problem (by resolving the question of whether California needed a site) to one more receptive to technical risk studies.)

\section{The role of risk analyses}

A great deal of attention has also been paid recently to the topic of technological risk assessment for problems such as the siting of facilities (see Conrad, 1980; Schwing \& Albers, 1980). It is of interest to examine the role that risk assessments have played in the California LNG case.

During the course of the LNG debate in California, six studies assessing the safety risks of the proposed terminals were conducted by the utility and local, state, and federal government agencies (for a critical review of these studies, see Mandl \& Lathrop, 1981). Several studies are of particular interest. The applicant commissioned a consulting firm, Science Applications Inc. (SAI), to do a study and the FERC produced its own risk assessment. Both reports showed very low numbers on various probabilistic measures of risk (expected fatalities per year and individual probability of fatality per year). These numbers were interpreted to mean that the risk was acceptable. A risk assessment produced by the consulting firm Socio-Economic Systems (SES) for the Oxnard municipal government suggested similarly low probabilistic measures of risk (though expected fatalities were 380 times higher than the applicant's assessment), but they interpreted the figures as unacceptably high.

One explanation lies in the format for presenting the results. The SAI study described maximum credible accidents (MCAS) without accompanying probabilities. Opposition groups interpreted these results as evidence that the terminal was not acceptably safe. The municipal government, originally in favor of the site, began to waver in its support, probably influenced by the apparent uncertainty of the risk and the strength of the opposition groups (Ahern, 1980). In sum, risk assessments did not provide a single, coherent assessment of acceptability of the risk of an LNG terminal; their results were subject to interpretation depending on party positions (Lathrop, 1980). In fact, risk assessments were used both to promote and to oppose terminal applications.

In reviewing the technical differences among the assessments leading to these conclusions, Lathrop and Linnerooth (in press) have shown that there are many degrees of freedom left to engineering and analytic judgment, including how to characterize risk, what formats to use for pre- 
sentation, what gaps to fill with assumptions, which of several conflicting models to use, how to portray the degree of confidence in the results, and what contingencies simply to leave out of the analysis.

This analytic freedom helps explain the differences among the above three Oxnard risk assessments. It can push the risk measurement in any direction. Very conservative assumptions can drive it up; omissions of inconvenient aspects such as terrorism can drive it down. Clear presentations of expert disagreements can decrease the confidence in the results, and so on. The final result may have as much to do with the predilections of the analyst as with the physical characteristics of the site or technology.

This finding takes on special significance when viewed in the context of the policy process. The MAMP model has illustrated that the risk assessments, though intended to advise a client on the safety of the proposed terminal, were, almost without exception, eventually used to support a party argument. For this reason, clear incentives exist for the analysts to present their results as persuasively as possible, which explains the tendency on their part to omit discussions on the uncertainty of their results and to choose presentation formats that present their case as strongly as possible.

\section{SUGGESTIONS FOR FUTURE RESEARCH}

The California case study illustrates that political decisions are messy when there are grave uncertainties regarding the risks and benefits of proposed projects. Interested parties hesitate to express their opinions too clearly because of a fear that they can be used against them. The arguments they actually use are designed to persuade, but may not represent their true objectives. Over time the parties may change their positions, either because they have reconsidered the problem in the light of new information or because an exogenous event occurs which creates a short-run crisis. These points have been alluded to in the recent literature on information processing as well as in the emerging literature on technology and risk assessment from an institutional perspective. (A set of papers on this subject appears in Conrad, 1980, and Kunreuther \& Ley (in press.)
The MAMP model should be viewed as a starting point for undertaking research which can improve the political process with respect to problems such as the siting of facilities. We have seen that formal risk analyses, especially risk assessments, are subjective exercises undertaken to support a specific party's arguments. Furthermore, the importance of these analyses will depend on the nature of the sequential decision process, the relevant interested parties which interact, and the type of conflicts produced between them. Given these descriptive observations, the following research areas appear to be promising avenues for the future.

\section{Establishing credibility of analyses}

In a recent paper Nelkin and Pollak (1979) indicate the inadequacy of existing institutions to deal with problems of conflicting evidence and polarized expert opinion with respect to questions such as risk assessments. As a way of dealing with this problem, they advocate the need to establish rules of evidence as a basis for making better decisions. Lathrop and Linnerooth (in press) provide a suggested set of guidelines with respect to establishing rules of evidence. In particular, they stress the importance of defining the risk being assessed, being clear on assumptions and error bounds as well as indicating the conditional nature of specific analyses which are undertaken.

There is a need for more field research which attempts to apply these criteria or others to a specific set of problems. One of the difficulties which currently exists is the lack of an institutional mechanism for evaluating the different risk assessments produced by different parties. Ackerman, Rosa-Ackerman, Sawyer \& Henderson (1974) point out that the traditional approaches such as legal responses, agency hearings, and judicial reviews have inherent limitations with respect to evaluating these conflicting assessments. The problem is especially difficult for the siting of new technologies where there are no objective measures of risk. Private consulting firms frequently undertake these analyses and have a built-in bias in telling the contracting party what they want to hear.

We feel that the policy recommendation 
suggested by Ackerman and co-workers, that one establish a review board to examine these assessments, deserves a trial for problems such as the LNG siting case discussed above. Under the proposed procedure the members, all of whom would be trained in subjects fundamental to technical analysis, would provide a written report evaluating the impact of specific assessments and specific issues (e.g., population risk, environmental impact). The authors urge that particular attention be given to specifying the empirical basis of the set of findings and how well the analysis is grounded in scientific theory.

\section{Research on facilitating collective action}

In a very stimulating paper, Buckley, Burns, and Meeker (1974) point out that existing institutional mechanisms and social relations among the interested parties significantly influence their response to a particular problem or issue. The MAMP model is an attempt to explore the type of interactions between the parties. The emphasis is, thus, on the decision process rather than simply on the outcomes, as in standard models of choice such as game theory, multiattribute utility theory, and cost-benefit analysis.

Buckley, Burns, and Meeker point out that one can help resolve conflicts and promote collective decision making by better structuring the environment in which decisions are made. For example, communication between the parties who disagree with each other on particular alternatives can be facilitated by having some type of mediator (e.g., a government agency) who hears opposing arguments as well as enforcing agreements made in an earlier round.

Future empirical research could examine the types of attributes one would like a decision process to satisfy. For example, one could ask, "Have each of the interested parties been satisfied with its role in the process?" "Were a wide enough set of alternatives considered so that the parties felt that a choice was actually being made?" The answers to these types of questions in a concrete problem context may also suggest specific policy recommendations. For example, if all interested parties were ex- pected to have excess to the same type of information (e.g., risk assessments evaluated by a review board) before evaluating different alternatives, then some type of institutional mechanism would be needed to achieve this objective.

In investigating process, there should be a recognition that certain factors may be more important in some cultural settings and less relevant in others. The promising work of Thompson (1981) and Douglas and Wildavsky (in press) on developing elements of a cultural theory of risk suggests that the constellation of different groups (e.g., castes, sects) and the type of interaction between then are important considerations in specifying approaches for promoting collective decision making. Nelkin and Pollak (1979) point out that appropriate procedures vary with national political styles. They note that the approach to solving conflicts in a political context of consensus and compromise will differ from that in an adversary culture.

\section{Policy instruments}

If interested parties have conflicting goals and objectives, it may be possible to design certain policy instruments to reallocate the costs and benefits so that there is more harmony between the groups. Two mechanisms that may be particularly relevant in this connection are insurance schemes and compensation systems.

Insurance may provide a way of protecting potential victims against potential property losses and physical injury. Today there is limited insurance protection against large-scale accidents such as a catastrophic accident of an LNG terminal. A General Accounting Office report (1978) concluded that under present liability arrangements injured parties could not be fully compensated for a serious accident. Some of the research questions which could be appropriately addressed in future problem-focused studies are:

- Which of the interested parties is liable in the event that a specific disaster occurs after a project has been sited?

- What types of enforcement procedures can be evoked to assure that contract provisions are satisfied ex post?

- Are there historical lessons which shed 
light on the role of insurance as a tool for providing financial protection to potential victims?

With respect to the more direct consequences of a siting a new facility, O'Hare (1977) has proposed a compensation system to deal with opposition to proposed sites from certain interested parties. For example, suppose residents of a community were concerned with suffering losses in property values as well as safety and environmental risks if the project were sited there. O'Hare proposes that each community determine a minimum level of per capita compensation for it to be willing to make a legal commitment to have the project in its backyard if the compensation is paid.

Further research is needed on the problems of such a system working in practice for a particular problem. In California, no facility was approved in part because compensation was not offered to the affected public who perceived themselves as losers. Buckley, Burns, and Meeker (1974) have suggested that changing the structure of payoffs may reduce conflicts of interest between the parties. On the other hand, it is not clear what type of payments would be necessary to appease opposition groups such as the Sierra Club.

From the above suggested topics it should be clear that there is considerable research of a prescriptive nature on risk which needs to be undertaken. The purpose of our cross-country comparisons of LNG siting decisions is to provide considerable data on how the politieal process appears to work in practice and the differences across countries. The MAMP model described in this paper has been found to be a useful framework for making comparisons between countries. The challenge for the future is to capitalize on our understanding of process to try and improve political decision making.

\section{REFERENCES}

Ackerman, B., Rosa-Ackerman, S., Sawyer, J., \& Henderson, D. The uncertain search for environmental quality. New York: The Free Press, 1974.

Ahern, W. "California meets the LNG terminal." Coastal Zone Management Journal, 1980, 7, 185-221, 1980.
Allison, G. T. Essence of decision. Boston: Little, Brown and Company, 1971.

Arrow, K. Social choice and individual values. New York: Wiley, 1963.

Bachrach, P., \& Baratz, M. Power and poverty. New York: Oxford University Press, 1970.

Braybrooke, D. Traffic congestion goes through the issue-machine. London: Routledge and Kegan Paul, 1974.

Braybrooke, D. Policy formation with issue processing and transformation of issues. In Hooker, Leach, $\&$ McClennen (Eds.), Foundations and applications of decision theory. Dordrecht, Holland: D. Reidl Publishing Company, 1978.

Buckley, W., Burns, T. \& Meeker, L. Structural resolution of collective action problems. Behavioral Science, 1974, 19, 277-297.

Cobb, R., \& Elder, C. D. Participation in American politics: The dynamics of agenda building. Baltimore, Maryland: Johns Hopkins University Press, 1972.

Conrad, J. (Ed.). Society, technology and risk assessment. London: Academic Press, 1980.

Cyert, R., \& March, J. A behavioral theory of the firm. Englewood Cliffs, New Jersey: Prentice Hall, 1963.

General Accounting Office. Need to improve regulatory review process for liquefied natural gas imports. Report to the Congress, ID-78-17, Washington, D.C., 1978.

Gershuny, J. What should forecasters do? A pessimistic view. In P. Baehr \& B. Wittrock (Eds). Policy analysis and policy innovation: Patterns, problems and potentials. London: Sage Publications, 1981.

Holling, C. S. Resilience in the unforgiving society. Working Paper R-24, Vancouver: Institute of Resource Ecology, 1981.

Kunreuther, H., \& Lathrop, J. Siting hazard facilities: The case of LNG terminals," Risk Analysis, in press.

Kunreuther, H., \& Ley, E. Decision processes and institutional aspects of risk. Proceedings of a Summer Study, June, IIASA Laxenburg, Austria, in press.

Lathrop, J. Decision-making on LNG terminal siting: California, U.S.A. Draft Report, IIASA, Laxenburg, Austria, 1981.

Lathrop, J., \& Linnerooth, J. The role of risk assessment in a political decision process. In P. Humphreys \& A. Vari (Eds.), Analysing and aiding decision processes. Amsterdam: North Holland, in press.

Levine, M. E., \& Plott, C. R. Agenda influence and its implications. Virginia Law Review, 1977, 63.

Lindblom, C. The science of muddling through. Public Administration Review, 1959, 19, 79-88.

Linnerooth, J. A short history of the California LNG terminal. WP-80-155, IIASA, Laxenburg, Austria, 1980.

Majone, G. Process and outcome in regulatory decisions. American Behavioral Scientist, 1979, 22, 561-583.

Mandl, C., \& Lathrop, J. Assessment and comparison of liquefied energy gas terminal risk. WP-81-098, IIASA, Laxenburg, Austria, 1981. 
March, J. G. 1981. Bounded rationality: Ambiguity and engineering of choice. Bell Journal of Economics, 1978, 9, 587-608.

March, J., \& Simon, H. Organizations, New York: Wiley, 1958.

Nelkin, D., \& Pollak, M. Public Participation in Technological Decisions: Reality or Grand Illusion. Technology Review, 1979, September, 55-64.

Neustadt, R. Assiance politics. New York, 1970

Office of Technology Assessment (OTA). Transportation of Liquefied natural gas. Washington, D.C.: Office of Technology Assessment, 1977.

O'Hare, M. 1977. Not on my block you don't: Facility siting and the strategic importance of compensation. Public Policy, 1977, 25, 409-58.

Schwing, R. C., \& Albers, W. A. (Eds.). Societal risk assessment: How safe is safe enough? New York: Plenum Press, 1980.
Simon, $\mathrm{H}$. The changing theory and changing practice of public administration. In I. de Sola Pool (Ed), Contemporary political science: Toward empirical theory. New York: McGraw Hill, 1967.

Stokey, E., \& Zeckhauser, R. A primer for policy analysis. New York: Norton, 1978.

Thompson, M. Risk and regime. IIASA Working Paper WP-81, Laxenburg, Austria, 1981.

Walker, J. Setting the agenda in the U.s. Senate: A theory of problem selection. British Journal of Political Science, 1977, 7, 423-445.

Wildavsky, A. The politics of the budgetary process. Boston: Little Brown and Co., 1964.

Wynne, B. Institutional mythologies and dual societies in the management of risk. Paper presented at Summer Study Meeting at IIASA, June, 1981.

(Manuscript received January 20, 1982) 


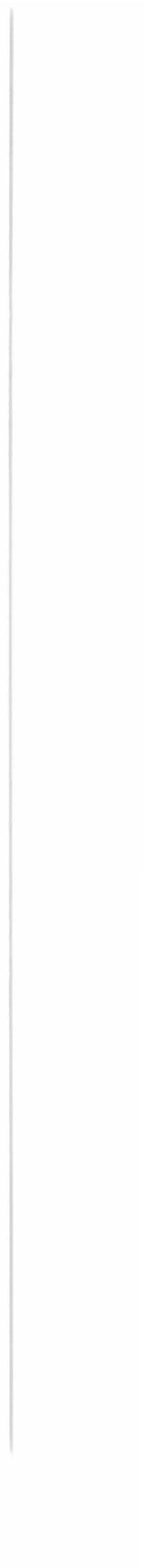

